\title{
Pancreatic pseudocyst: Dilemma of its recent management (Review)
}

\author{
JONATHAN HARTANTO TAN, WENJIE CHIN, ABDUL LATEEF SHAIKH and SHUSEN ZHENG
}

\begin{abstract}
Division of Hepatobiliary and Pancreatic Surgery, Department of Surgery, The First Affiliated Hospital, School of Medicine, Zhejiang University, National Health Commission of China Key Laboratory of Combined Multi-Organ

Transplantation, Key Laboratory of Diagnosis and Treatment of Organ Transplantation, Chinese Academy of

Medical Sciences, Key Laboratory of Organ Transplantation, Hangzhou, Zhejiang 310003, P.R. China
\end{abstract}

Received December 7, 2019; Accepted March 21, 2020

DOI: $10.3892 / \mathrm{etm} .2020 .9590$

\begin{abstract}
Advances in radiological techniques have led to an increase in the number of diagnoses of pancreatic pseudocyst, which is the most common pancreatic cyst lesion disease, accounting for two-thirds of all pancreatic cyst lesions. Historically, the management of pancreatic pseudocyst has been achieved through the use of conservative treatments and surgery; however, due to the complications and recurrence rate associated with these techniques, the management of pancreatic pseudocyst is challenging. Surgeons and gastroenterologists have attempted to determine the optimal management technique to treat pancreatic pseudocyst to reduce complications and the recurrence rate. From these investigations, percutaneous catheter, surgical and endoscopic drainage with ultrasonography guidance have become promising management techniques. The present review aimed to summarize the diagnostic and therapeutic methods used for the management of pancreatic pseudocyst and to compare percutaneous catheter, surgical and endoscopic drainage.
\end{abstract}

\section{Contents}

1. Introduction

2. Review criteria

3. Classification

4. Incidence

Correspondence to: Professor Shusen Zheng, Division of Hepatobiliary and Pancreatic Surgery, Department of Surgery, The First Affiliated Hospital, School of Medicine, Zhejiang University, National Health Commission of China Key Laboratory of Combined Multi-Organ Transplantation, Key Laboratory of Diagnosis and Treatment of Organ Transplantation, Chinese Academy of Medical Sciences, Key Laboratory of Organ Transplantation, 79 Qingchun Road, Hangzhou, Zhejiang 310003, P.R. China

E-mail: shusenzheng@zju.edu.cn

Key words: pancreatic, pseudocyst, management, drainage

\author{
5. Diagnosis \\ 6. Treatment \\ 7. Conclusion
}

\section{Introduction}

A pancreatic pseudocyst is a localized fluid collection, which is rich in amylase and other pancreatic enzymes, contains no solid material and is surrounded by a well-defined wall of fibrous tissue lacking an epithelial lining (1). The majority of pancreatic pseudocyst occur as a common complication of chronic pancreatitis, but they may also occur during acute pancreatitis or pancreatic trauma or following pancreatic surgery $(2,3)$. The increase in the incidence rates of pancreatitis and the advancements made in radiological techniques have facilitated an increased number of diagnoses of pancreatic pseudocyst. Pancreatic pseudocyst is the most common type of pancreatic cyst lesion, with the incidence accounting for two thirds of all pancreatic cystic lesions, compared with pancreatic cystic neoplasm, which only accounts for 10-15\% (4). Although pancreatic pseudocyst does not lead to malignancies as frequently as other types of pancreatic lesion, it is important to note that there is a group of tumors with malignant potential, including serous cystadenomas (SCAs), mucinous cystic neoplasms (MCNs) and intraductal papillary mucinous neoplasms (IPMNs) (5). Pancreatic pseudocyst may be distinguished from these lesions by using evaluation of enzymatic and tumor markers from the cystic fluid obtained by fine-needle aspiration (FNA), which is worthwhile, as misidentification of lesions may lead to incorrect management and far-reaching consequences $(6,7)$. Previously, pancreatic pseudocyst was traditionally managed by open surgical drainage (SD) (8) and other management techniques include percutaneous catheter drainage (PCD) and endoscopic drainage (ED) (9-12). The optimal method to manage pseudocyst and the best time and choice to administer invasive treatment over conservative treatment options remains under debate. Numerous studies have reported the success of these management techniques; however, fewer studies have compared each treatment technique in a significant number of patients. The present study aimed to review the classification, incidence, and diagnosis of pancreatic pseudocyst, in addition to comparing techniques for its management. 


\section{Review criteria}

The present review investigated the classification of pancreatic pseudocyst, incidence rate, diagnostic tools and the management options for pancreatic pseudocyst. Only comparative studies were considered for review and only full studies were used. In a search in the PubMed database from 1990 until 2019, the medical subject heading term 'pancreatic pseudocyst' and the text search terms 'pseudocyst drainage', 'surgical drainage', 'endoscopic drainage', 'cystogastrostomy', 'gastrojejunostomy', 'cystoduodenostomy', 'transpapillary drainage', 'transmural drainage' and 'esophagogastroduodenoscopy' were used, either alone or in combination.

\section{Classification}

There are numerous classification systems for pseudocysts, including that by D'Egidio and Schein (13) from 1991, in which pseudocysts were classified based on the underlying etiology of acute or chronic pancreatitis, pancreatic duct anatomy and the presence of communication between the cyst and the pancreatic duct. Using this classification system, the cyst may be divided into three distinct types: Type I, defined as an acute post-necrotic pseudocyst, which occurs after an episode of acute pancreatitis, and it is associated with normal duct anatomy and rarely communicates with the pancreatic duct; Type II, also a post-necrotic pseudocyst, which occurs after an incidence of acute or chronic pancreatitis, exhibits signs of an abnormal pancreatic duct and frequently communicates with the pseudocyst; and Type III, which is defined as a retention pseudocyst, occurs during chronic pancreatitis, is associated with the pancreatic duct structure/obstruction and pseudocyst to duct communication is present. In 2002, Nealon and Walser (14) proposed a more simple classification based on the pancreatic duct anatomy from endoscopic retrograde cholangiopancreatography (ERCP), which is provided in Table I.

In 2015, using a large retrospective study of 893 patients with pancreatic pseudocyst, Pan et al (9) proposed a new classification based on the anatomical location and clinical manifestation of the pseudocysts, along with the relationship between the cyst and the pancreatic duct (Table II).

\section{Incidence}

Pseudocysts account for two-thirds of all pancreatic cyst lesions and are therefore more common than those caused by a pancreatic cyst neoplasm, which account for 10-15\% of all pancreatic cyst lesions (4). The incidence of pseudocysts is $1.6-4.5$ per 100,000 adults each year $(2,15)$ and the prevalence ranges from $10-20 \%$ in acute pancreatitis and $20-40 \%$ in chronic pancreatitis (16). In one study on patients with chronic pancreatitis who presented with pseudocyst, 70-78\% had alcohol-induced chronic pancreatitis, 6-16\% had idiopathic chronic pancreatitis and 6-8\% had chronic biliary pancreatitis (17). In addition to pancreatitis, several patients in another previous study also presented with pancreatic pseudocyst following a history of trauma; Walt et al (18) reported that among 357 patients, there were 17 patients (5\%) with a history of blunt trauma, four patients $(1 \%)$ who had a penetrating trauma and one patient $(0.3 \%)$ with operative trauma.

\section{Diagnosis}

The majority of pancreatic pseudocyst occur following pancreatitis, either acutely or chronically $(15,19)$, which makes the history of pancreatitis of the patients crucial. The clinical presentation of patients with pancreatic pseudocyst exhibits a broad variation, from being asymptomatic to major abdominal catastrophe due to complications (20). Thus, there are no specific symptoms for pseudocysts; however, the most frequent symptom is abdominal pain (76-94\%), nausea and vomiting (50\%) and weight loss (20-51\%). Occasionally, patients present with jaundice, fever and pleural effusion from complications of the pseudocysts or even sepsis from an infected pseudocyst $(21,22)$.

The most effective diagnostic tools for the cystic pancreatic lesion are imaging modalities. With its portability and ease of access, transabdominal ultrasonography (US) has become the most used diagnostic tool in evaluating pseudocysts (23); pseudocysts are reported to have an apparent anechoic structure with distal acoustic enhancement on US. In the majority of cases, the pseudocyst will appear round or oval with a smooth wall and clear debris; however, under special conditions, such as hemorrhages or infected cysts, the phenotype of pseudocysts may appear more complex. In addition, Color Doppler should be performed to ensure that the lesion is not a pseudoaneurysm. Due to its high operator dependence and its limitation of overlying bowel gas, the sensitivity range is $70-90 \%$, making it less sensitive compared to CT, which has a sensitivity of $90-100 \%$ (24). On CT, pseudocysts exhibit fluid density ( $<15$ Hounsfield Units), with a well-defined wall. The wall is smooth and symmetric but varies in appearance, either thin, which is barely perceptible or thick, which displays as a contrast enhancement $(25,26)$. On CT, it is possible to differentiate between a pseudocyst and walled-off necrosis by recognizing solid components and debris. In addition, CT scans provide detailed information regarding the surrounding anatomy and they are able to highlight additional pathologies, including pancreatic duct dilatation and calcifications, common bile duct dilatation and the extent of the pseudocyst. However, it is challenging to differentiate between a pseudocyst and cyst neoplasm on CT (27).

MRI and magnetic resonance cholangiopancreatography are the most sensitive and accurate diagnostic tools for pancreatic pseudocyst. MRI is also sensitive in detecting bleeding and complex fluid collections. Pseudocysts generally exhibit $\mathrm{T} 1$ hypointensity and T2 hyperintensity, hemorrhage or the accumulation of proteinaceous fluid, which may promote $\mathrm{T} 1$ hyperintensity (28). The two techniques are considered to be superior to CT scans in describing debris within the fluid collections, but they are generally not routinely used as, for the majority of cases, CT scans offer all of the diagnostic information that is required.

ERCP is not necessary for diagnosing pseudocyst; however, it remains the gold standard technique for the diagnosis of pancreatic duct disruption and may be more useful for therapeutic purposes (29). Nealon and Walser (19) investigated the use of ERCP for the treatment of pseudocyst and acute pancreatitis and reported that ERCP may influence the treatment plan. Therefore, certain studies have recommended the use of the ERCP procedure prior to contemplating surgical procedures. 
Table I. Classification of pancreatic pseudocyst concerning the pancreatic ductal anatomy.

A, Acute pancreatitis

Type Description $\quad$ Illustration

I Normal duct/no communication

II

Normal duct/with communication

III

Normal duct with stricture/no communication

IV

Normal duct with stricture/with communication

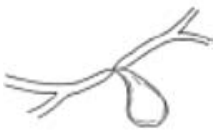

Normal duct/ complete obstruction

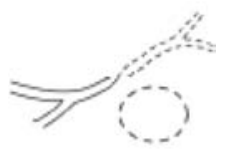

B, Chronic pancreatitis

\begin{tabular}{lll}
\hline Type & Description & Illustration \\
\hline
\end{tabular}

VI

Abnormal duct/no communication

VII

Abnormal duct/with communication
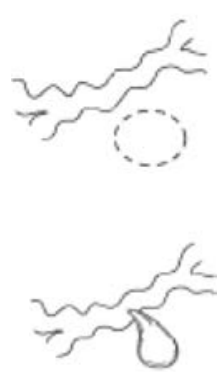

Another imaging technique used is endoscopic US (EUS); this technique provides high-quality images due to the close proximity of the transducer and area of interest, providing a sensitivity range of $93-100 \%$ and a specificity range of $92-98 \%$ for the distinction of pancreatic pseudocyst, making it a better technique than CT and US (30). EUS is never used alone to diagnose pseudocyst, and it is mostly used as a secondary test to further evaluate pancreatic cysts detected by other modalities (US, CT or MRI). EUS may also be used to guide ED therapy and FNA to evaluate cyst fluid (31).
Hammel et al (7) studied 50 pancreatic cystic lesions from 43 patients (31 pancreatic pseudocyst, 7 SCAs and $12 \mathrm{MCNs}$ ) to evaluate enzymatic (amylase and lipase) and tumor markers [carcinoembryonic antigen (CEA), cancer antigen (CA)125 and CA19-9] in the fluid of cysts obtained by FNA to differentiate the cystic pancreatic lesion. The results revealed that high amylase levels of $>5,000 \mathrm{U} / \mathrm{ml}$ had a $94 \%$ sensitivity rate and a $74 \%$ specificity rate for distinguishing pseudocysts from other cystic lesions. Decreased CEA levels were also detected in SCAs and patients with pancreatic pseudocyst. In addition, a previous study by Sperti et al (32) comprising 48 patients 
Table II. Classification of pancreatic pseudocyst.

\begin{tabular}{ll}
\hline Type & \\
\hline I & $<5$ cm without symptoms, complications and neoplasia \\
II & Suspected for cystic neoplasia \\
III & Pseudocyst located in the pancreatic uncinate process \\
IIIa & Communication with pancreatic duct $(+)$ \\
IIIb & Communication with pancreatic duct $(-)$ \\
IV & Pseudocyst located in head, neck or body of pancreas \\
IVa & Communication with pancreatic duct $(+)$ \\
IVb & Distance of cyst to gastrointestinal wall is $<1 \mathrm{~cm}$ \\
IVc & Neither IVa nor IVb applies \\
V & Pseudocyst located in the pancreatic tail \\
Va & Splenic vein involvement or upper gastrointestinal bleeding \\
$\mathrm{Vb}$ & Distance from the cyst to gastrointestinal wall is $<1 \mathrm{~cm}$, without splenic vein involvement or upper \\
& gastrointestinal bleeding \\
\hline
\end{tabular}

with pancreatic cysts ( 21 pseudocysts, 7 SCAs, 14 MCNs and 6 IPMNs) indicated that tumor markers including CA19-9 and CA72-4 were significantly increased in MCNs and PCMNs. In addition, with combined tumor markers, 19 out of 20 premalignant lesions (95\%) were correctly identified with only 1 false-positive result (3.6\%). Therefore, evaluation of cyst fluids from FNA is useful for distinguishing pancreatic pseudocyst from other malignant cystic diseases.

\section{Treatment}

Selection of treatment. When selecting the therapeutic approach and making management decisions for pancreatic pseudocyst, the size and location of the cyst, correlation and dilatation of the main pancreatic duct, pancreatic pathology and the symptoms of the patients should be considered (33). However, not every pancreatic pseudocyst patient presents with obvious symptoms, in a study examining the history of pancreatic pseudocysts in 75 patients by Yeo et al (25), 36 patients were found to be asymptomatic and they also failed to find any reliable indicators, such as the size or duration, to predict which patients are likely to become symptomatic and require treatment. During the natural progression of pancreatic pseudocyst, the early phase, which has a duration of six weeks, is when spontaneous resolution is most likely to occur (25). Following the early phase, pseudocysts were previously considered to have a mature wall and higher risk of complications, requiring intervention management. However, several recent studies have emphasized that asymptomatic and minimally symptomatic pancreatic pseudocyst identified through a CT scan or US may be managed conservatively without intervention management; it is considered that $40 \%$ of these cases are spontaneously resolved (11). Patients who were more likely to have an intervention procedure were those with the following: i) Complicated pseudocyst like compression of major veins; gastric or duodenal obstruction; compression of main bile duct; associated with pancreatic ascites or a pancreatic-pleural fistula; infected pancreatic pseudocyst; or hemorrhage in pancreatic pseudocyst.ii) Symptomatic pseudocyst with a feeling of satiety, nausea, vomiting, severe abdominal pain and/or back pain or upper gastrointestinal bleeding. iii) Asymptomatic pseudocysts $>6 \mathrm{~cm}$ without any regression for $>6$ weeks. iv) Patients with an extrahepatic pseudocyst $(13,22,26)$. The comparative study of intervention treatment in pancreatic pseudocyst shown in Table III.

$P C D$. There are several PCD techniques, including simple percutaneous aspiration drainage and continuous percutaneous drainage, which are both achieved through the help of a US or CT scan. Drainage is performed via a 7-12 French (Fr) pigtail catheter, which is inserted into the pseudocyst via needle-inserted guidewires. Simple percutaneous aspiration drainage has been discovered to be less effective than continuous percutaneous drainage. Several previous studies have indicated that PCD has a higher risk of complications associated with infection compared with SD or ED, alongside a longer hospital stay $(34,35)$. However, the study also reported that PCD was an effective treatment for pancreatic pseudocysts that arose from acute pancreatitis patients, but not for pancreatic pseudocyst in chronic pancreatitis patients (16). Loveday et al (36) identified that the majority of the guidelines recommend PCD for treating infected pancreatic pseudocyst. A comparison of PCD and SD by Adams and Anderson (37) concluded that PCD may be performed to avoid a major abdominal operation when symptomatic pancreatic pseudocyst are $>5 \mathrm{~cm}$ in size without pancreatic duct obstruction. However, the disadvantage of this procedure is the long external pancreatic fistula, which carries a substantially high risk of secondary infections of the catheter track. Compared with the endoscopic treatment, PCD had an equal technical success rate and clinical success rate, with longer hospital stays and higher rates of reintervention. In a study on 173 patients, Heider et al (34) reported a different result; it was concluded that unselected patients treated with PCD demonstrated a higher failure rate, higher mortality and morbidity rate and required more long-term hospitalization compared with those 


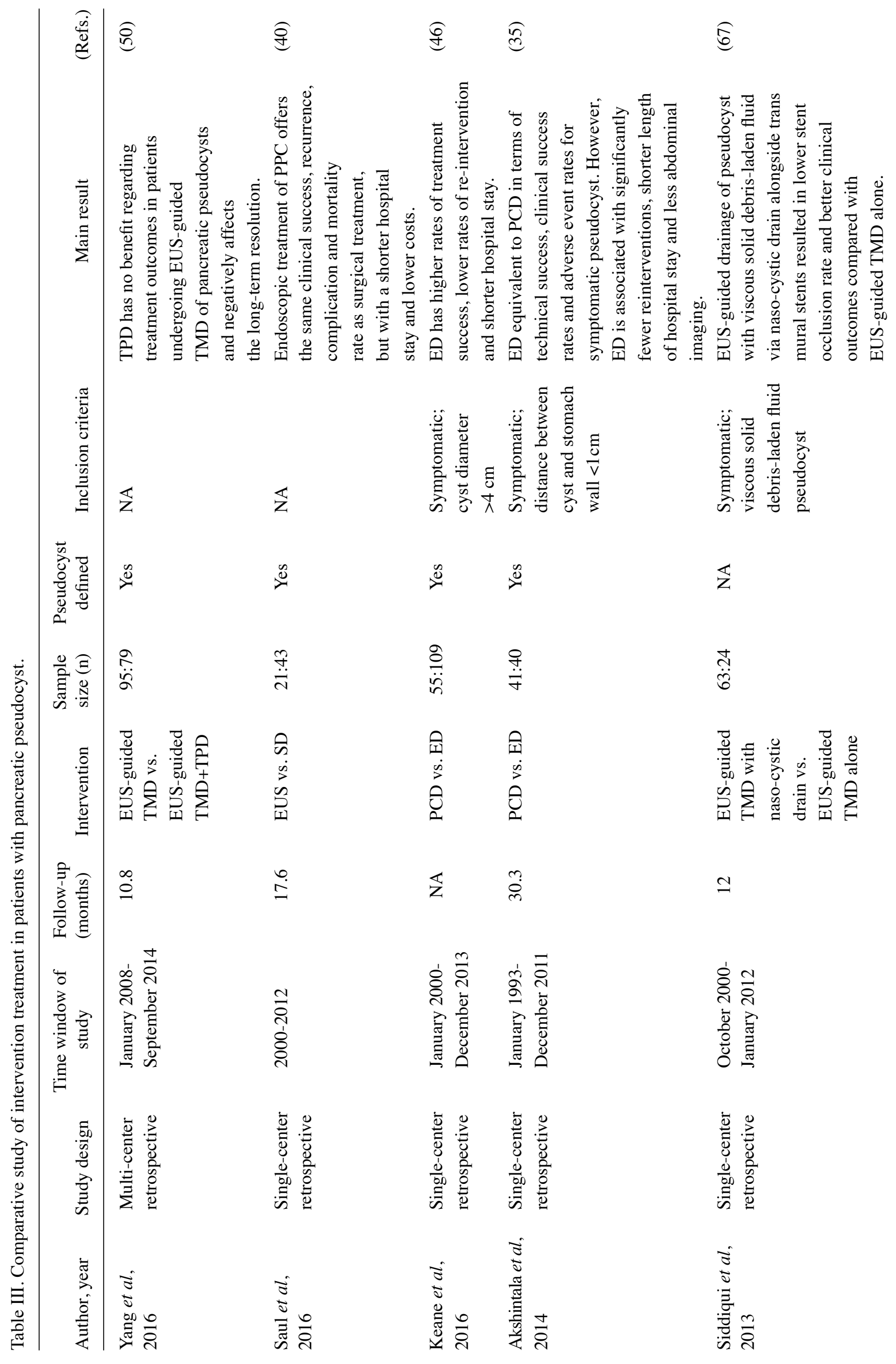




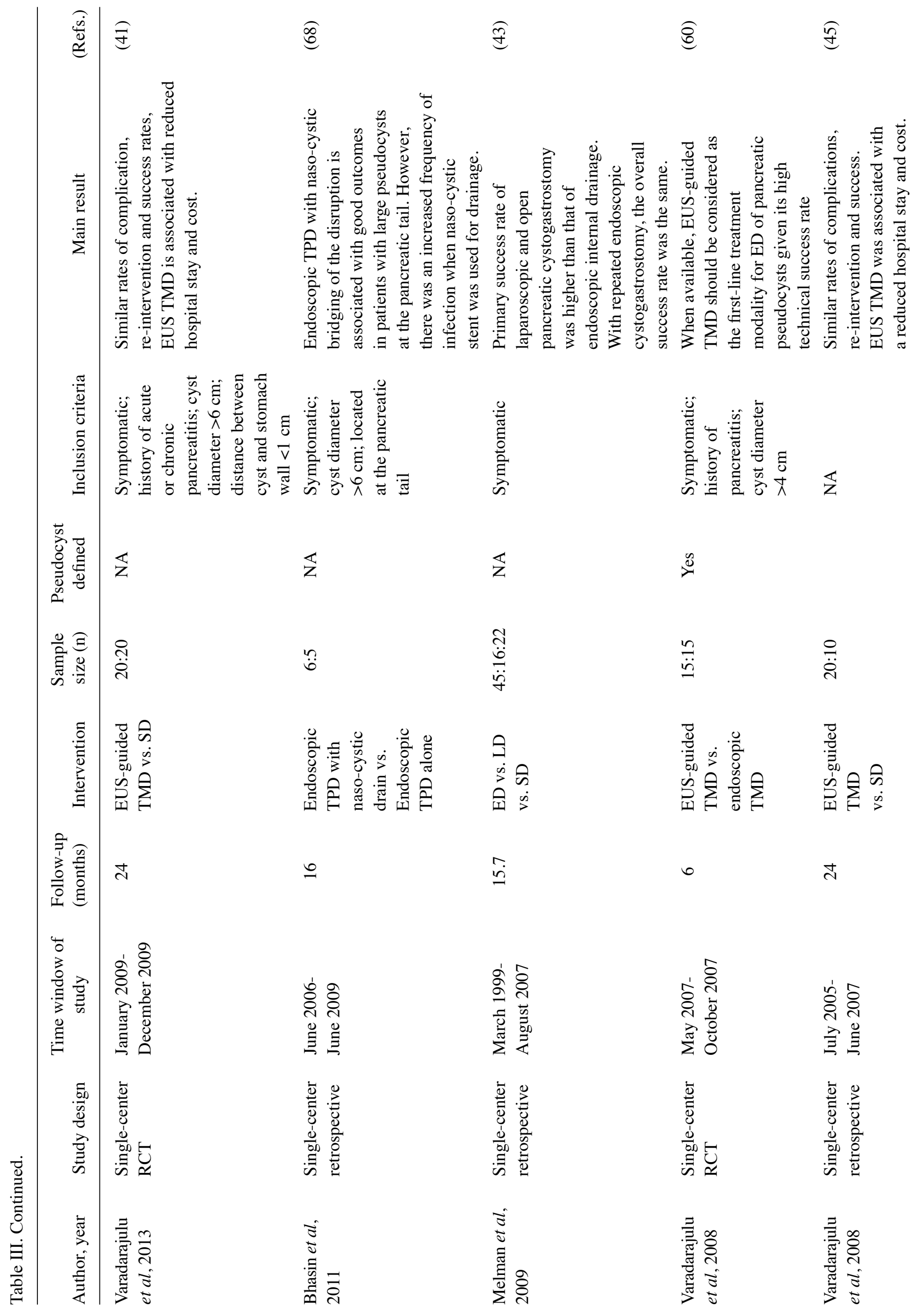




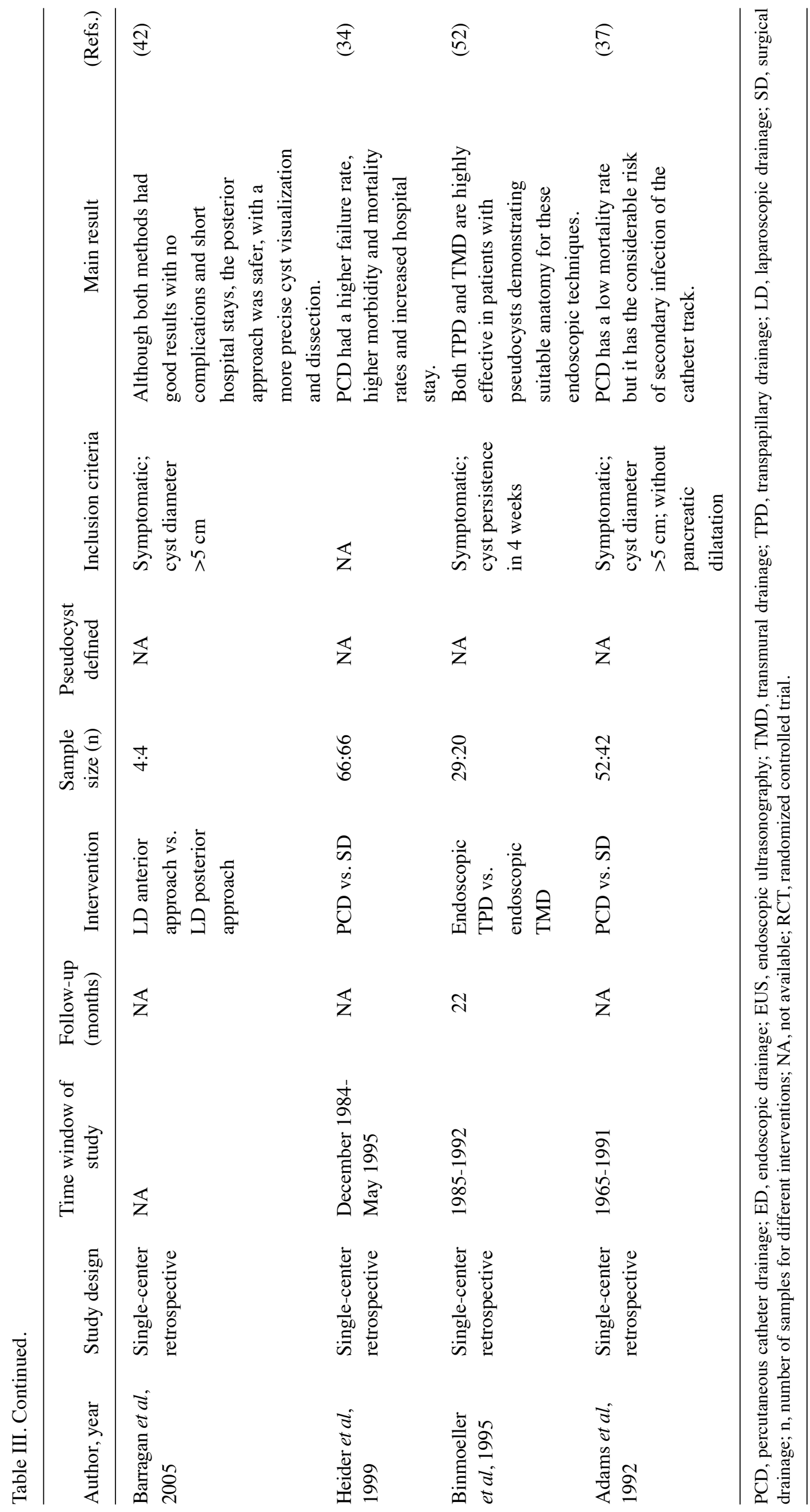


treated by surgery. Thus, PCD should only be recommended for patients who are not eligible for surgical treatment.

Surgical treatment. Pancreatic pseudocyst have been treated using surgery for over a decade and this is still frequently used as a treatment option. The surgical treatment of pancreatic pseudocyst entails internal drainage into the stomach, duodenum and jejunum, external drainage and resection. Jedlicka (38) performed the first pseudocystgastrostomy in 1921. Since then, numerous studies have reported excellent operative results, which has made SD the first-line therapy choice for symptomatic pancreatic pseudocyst; it demonstrates a permanent resolution of $91-97 \%$ in cystogastrostomy and cystojejunostomy, with mortality rates of $0-13 \%$ and morbidity rates of $10-30 \%$ (39). However, reoperation is not uncommon in SD, particularly for patients with chronic pancreatitis and persistent alcohol abuse. The majority of modern studies have compared SD with a minimally invasive technique, such as ED; most concluded that SD and ED shared similar success rates, complications and re-intervention rates; however, treatment with ED was associated with lower costs and shorter hospital stays, making ED superior to SD $(40,41)$. However, there remains a clear preference for the open surgical treatment of pseudocysts. For instance, a pseudocyst located in the pancreatic tail far away from the gastrointestinal lumen meant that ED was not a good treatment choice and due to its close proximity to the spleen, there was an increased risk of injury and hemorrhage, even with the PCD technique; thus, under those circumstances, SD was the best choice for treatment. Certain other indications for preferential surgical treatment are i) contraindication or failure of endoscopic or radiological methods; ii) complex main pancreatic duct stricture; iii) complex pathology such as an inflammatory mass in the pancreatic head; iv) main bile duct stricture caused by pseudocyst compression; v) venous occlusive disease; vi) multiple pseudocysts; vii) pseudocyst of the pancreatic tail; viii) hemorrhage not adequately controlled by angiographic embolization; and ix) suspicion of neoplastic cysts (39).

Laparoscopic cystogastrostomy has become another promising technique for minimally invasive treatment in addition to ED. The laparoscopic procedure may be accomplished using an anterior approach or a posterior approach; the use of these two techniques is based on the experience of the operator (42). In the anterior approach, a $4-\mathrm{cm}$ anterior gastrostomy is made with a harmonic scalpel to access the gastric mucosa, and a laparoscopic ultrasound probe is used to identify the location of the pseudocyst behind the gastric mucosa. After certifying the location, a harmonic scalpel is used to create a cystogastrostomy opening to drain the pseudocyst, and the anterior gastrostomy is then closed. In the posterior approach, a harmonic scalpel is used to divide the gastrocolic ligament, facilitating the entry to the lesser sac and access to the pancreas. A laparoscopic ultrasound probe is then used to locate the pseudocyst and a cystogastrostomy is then made with a stapler between the cyst and posterior gastric wall. This posterior approach is more difficult than the anterior approach; however, the visualization of the pseudocyst is clearer and the surgeon is able to remove more of the pseudocyst to allow the pathologist to rule out malignancy. With the anterior approach, smaller biopsies may be taken without the requirement for direct visualization of the pseudocyst. In a study of 83 patients by Melman et al (43), it was concluded that laparoscopic cystogastrostomy had a higher primary success rate compared with endoscopic cystogastrostomy. Out of 45 patients who underwent ED, 22 patients (48.9\%) required a secondary treatment, such as surgical cystogastrostomy, percutaneous drainage or repeated endoscopic drainage, to achieve the same success rate as that of laparoscopic drainage.

$E D$. The ED procedure was first performed in 1989 and it has since evolved as an accepted alternative to surgery when intervention is required (44). This technique has now become the preferred therapeutic approach due to being less invasive than surgery; it avoids external drainage with the risk of tube infection and has a high long-term success rate $(40,45,46)$. The aim of ED in the treatment of pancreatic pseudocyst is to make a connection between the pseudocyst and the gastrointestinal tract, either with the stomach, duodenum or even jejunum (36,47-49). There are two techniques that are used for ED: Transmural drainage (TMD) and transpapillary drainage (TPD); however, there is a lot of debate surrounding these two types of drainage technique and the determination of which technique is best for treatment (50-52). The judgment of whether to perform TMD or TPD is based on the cyst location, the connection of the cyst with the main pancreatic duct, obstruction of the pancreatic duct and the personal experience of the surgeon. However, there remains no guidance for choosing between these two techniques (53-55). TPD involves balloon dilation and stenting under ERCP, which should be performed routinely to identify the disruption or stenosis of the pancreatic duct (54). This technique requires communication between the main pancreatic ducts with the pseudocyst or the ability to cross any strictures to insert the 5-7 Fr plastic pancreatic stent. TMD may be achieved across the duodenal or gastric wall, depending on the pseudocyst location. The requirements for TMD include a $<1 \mathrm{~cm}$ distance between the pseudocyst and intestinal wall on imaging, a clear compression of the intestinal wall on endoscopy, the absence of varices, the absence of pseudoaneurysms and the exclusion of malignant lesions prior to treatment $(51,56)$. TMD begins with a pseudocyst puncture through the compression site of the gastric or duodenal wall to initiate the spontaneous drainage of the fluid; the cyst-gastrostomy (duodenostomy) fistula is pneumatically dilated with $8-15 \mathrm{~mm}$ biliary balloon dilators and 9-10 Fr straight or pigtail plastic stents may be passed into the cyst with the help of a guidewire $(57,58)$. It has been reported that a combination of these two drainage techniques may be performed if the pseudocyst does not heal after a single drainage procedure (55). However, combining this ED technique remains controversial, as Yang et al (50) indicated that the combination of TPD did not provide a benefit on the treatment outcome in patients undergoing TMD.

With the development of the ED technique, certain centers combine the use of conventional ED with US, which is referred to as EUS drainage, to ascertain the location of the cyst and its distance to the intestinal wall (59). The majority of studies have concluded that EUS drainage is superior compared with conventional $\mathrm{ED}$, providing more precise imaging of the pseudocyst and the surrounding anatomy, which may guide the operator to select the optimal puncture sites and avoid blood 
vessels $(60,61)$. These results make the intra- and post-operative complications of EUS drainage less severe compared with conventional ED.

Although EUS-guided TMD with plastic stents appears promising, several complications may still occur, including infection, perforation, migration and bleeding. The migration of the plastic stent is not uncommon; it was discovered to occur in $4-6 \%$ of patients who had EUS-guided TMD with plastic stents $(62,63)$. Therefore, several studies are searching for a better stent that may be used to achieve a higher success rate with less complications, including stent migration $(62,64,65)$. In a meta-analysis study by Yoon et al (66), it was discovered that the use of a metal stent in EUS-guided TMD was better than a plastic stent, demonstrating a higher success rate and lower adverse events in patients with pseudocysts, as well as patients with walled-off necrosis. Thus, metal stents are considered to be a better choice for the EUS-guided TMD technique for the treatment of pancreatic pseudocyst. In addition, Yao et al (56) performed a comparative study of EUS-guided TMD using self-expanding biflanged metal stent (BFMS) and tubular metal stent, indicating that both have equal efficacy, whereas BFMS was associated with fewer complications and less additional plastic stent placement.

EUS is also capable of guiding the drainage of debris or infected pseudocysts using naso-cystic drainage. A study by Siddiqui et al (67) discovered that drainage of pseudocysts with viscous solid debris-laden fluid by stent and naso-cystic tubes alongside the EUS-guided TMD technique had a three times greater short-term success rate compared with drainage of pseudocysts by EUS-guided TMD with a stent alone. During the long-term follow-up, it was determined that the complete resolution in pseudocysts drained by a stent alone was decreased (58\%) compared with that achieved by naso-cystic drainage (79\%). In addition, the rate of stent occlusion was lower $(13 \%)$ in naso-cystic drains compared with that obtained with stents alone (33\%). In addition to infected pseudocysts, Bhasin et al (68) compared 11 patients with non-infected symptomatic large pseudocysts located in the pancreatic tail, of which six patients received EUS-guided TPD with naso-cystic drainage and five patients received EUS-guided TPD alone. The results indicated that EUS-guided TPD combined with naso-cystic drains was associated with an improved outcome in patients with large pseudocysts in the pancreatic tail compared with EUS-guided TPD alone; however, the frequency of infection was increased alongside the use of naso-cystic stents.

\section{Conclusion}

Advancements in the radiological technique have led to an increase in the diagnostic rates of pancreatic cystic lesions. Imaging modalities, enzymatic evaluation and tumor marker evaluation have all become essential tools for diagnosing pancreatic pseudocyst and for differentiating pseudocysts from other cystic lesions. Intervention management, such as PCD, SD and ED may be considered if there are complications associated with the pseudocyst, in symptomatic cases of pseudocyst, if the pseudocyst has a diameter of $>6 \mathrm{~cm}$ or for patients that fail to respond to conservative management techniques. PCD techniques have become a simple technique to treat pancreatic pseudocyst with a high risk of secondary catheter infection; however, SD is still considered the gold standard treatment option for managing pancreatic pseudocyst with a high success rate, whereas the laparoscopic technique is becoming a promising minimal invasive surgical technique. Like SD, ED with US guidance has a high success rate, with a shorter hospital stay and decreased costs for the patients compared to SD; thus, this is currently the preferred technique. The majority of comparative studies on the treatment of pancreatic pseudocyst have a small study group, and thus, a larger comparative study group is required to further compare the management techniques for pancreatic pseudocyst.

\section{Acknowledgements}

Not applicable.

\section{Funding}

No funding was received.

\section{Availability of data and materials}

Not applicable.

\section{Authors' contributions}

JHT designed the present review article; JHT and WC were responsible for the collection and collation of the articles/published data, and for their inclusion in this review and interpretation; JHT, WC and ALS were responsible for data acquisition; JHT wrote the manuscript; ALS and SZ contributed to the critical revision of the manuscript for important intellectual content. All authors read and approved the final manuscript.

\section{Ethics approval and consent to participate}

Not applicable.

\section{Patient consent for publication}

Not applicable.

\section{Competing interests}

The authors declare that they have no competing interests.

\section{References}

1. Habashi S and Draganov PV: Pancreatic pseudocyst. World J Gastroenterol 15: 38-47, 2009.

2. Rosso E, Alexakis N, Ghaneh P, Lombard M, Smart HL, Evans J and Neoptolemos JP: Pancreatic pseudocyst in chronic pancreatitis: Endoscopic and surgical treatment. Dig Surg 20: 397-406, 2003.

3. Agalianos C, Passas I, Sideris I, Davides D and Dervenis C: Review of management options for pancreatic pseudocysts. Transl Gastroenterol Hepatol 3: 18, 2018.

4. Tran Cao HS, Kellogg B, Lowy AM and Bouvet M: Cystic neoplasms of the pancreas. Surg Oncol Clin N Am 19: 267-295, 2010.

5. Brugge WR, Lauwers GY, Sahani D, Fernandez-del Castillo C and Warshaw AL: Cystic neoplasms of the pancreas. N Engl J Med 351: 1218-1226, 2004. 
6. Warshaw AL and Rutledge PL: Cystic tumors mistaken for pancreatic pseudocysts. Ann Surg 205: 393-398, 1987.

7. Hammel P, Levy P, Voitot H, Levy M, Vilgrain V, Zins M, Flejou JF, Molas G, Ruszniewski P and Bernades P: Preoperative cyst fluid analysis is useful for the differential diagnosis of cystic lesions of the pancreas. Gastroenterology 108: 1230-1235, 1995.

8. Yemos K, Laopodis B, Yemos J, Scouras K, Rissoti L, Lainas A, Patsalos C, Tzardis P and Tierris E: Surgical management of pancreatic pseudocyst. Minerva Chir 54: 395-402, 1999.

9. Pan G, Wan MH, Xie KL, Li W, Hu WM, Liu XB, Tang WF and $\mathrm{Wu} \mathrm{H}$ : Classification and management of pancreatic pseudocysts. Medicine (Baltimore) 94: e960, 2015.

10. Froeschle G, Meyer-Pannwitt U, Brueckner $M$ and Henne-Bruns D: A comparison between surgical, endoscopic and percutaneous management of pancreatic pseudocysts-long term results. Acta Chir Belg 93: 102-106, 1993.

11. Cheruvu CV, Clarke MG, Prentice M and Eyre-Brook IA: Conservative treatment as an option in the management of pancreatic pseudocyst. Ann R Coll Surg Engl 85: 313-316, 2003.

12. Teoh AY, Dhir V, Jin ZD, Kida M, Seo DW and Ho KY: Systematic review comparing endoscopic, percutaneous and surgical pancreatic pseudocyst drainage. World J Gastrointest Endosc 8: 310-318, 2016.

13. D'Egidio A and Schein M: Pancreatic pseudocysts: A proposed classification and its management implications. Br J Surg 78: 981-984, 1991.

14. Nealon WH and Walser E: Main pancreatic ductal anatomy can direct choice of modality for treating pancreatic pseudocysts (surgery versus percutaneous drainage). Ann Surg 235: 751-758, 2002 .

15. Kim KO and Kim TN: Acute pancreatic pseudocyst: Incidence, risk factors, and clinical outcomes. Pancreas 41: 577-581, 2012.

16. Aghdassi AA, Mayerle J, Kraft M, Sielenkämper AW, Heidecke CD and Lerch MM: Pancreatic pseudocysts-when and how to treat? HPB (Oxford) 8: 432-441, 2006.

17. Klöppel G: Chronic pancreatitis, pseudotumors and other tumor-like lesions. Mod Pathol 20 (Suppl 1): S113-S131, 2007.

18. Walt AJ, Bouwman DL, Weaver DW and Sachs RJ: The impact of technology on the management of pancreatic pseudocyst. Fifth annual Samuel Jason Mixter Lecture. Arch Surg 125: 759-763, 1990.

19. Nealon WH and Walser E: Duct drainage alone is sufficient in the operative management of pancreatic pseudocyst in patients with chronic pancreatitis. Ann Surg 237: 614-622, 2003.

20. Redwan AA, Hamad MA and Omar MA: Pancreatic pseudocyst dilemma: Cumulative multicenter experience in management using endoscopy, laparoscopy, and open surgery. J Laparoendosc Adv Surg Tech A 27: 1022-1030, 2017.

21. Vignesh S and Brugge W: Endoscopic diagnosis and treatment of pancreatic cysts. J Clin Gastroenterol 42: 493-506, 2008.

22. Magyar A, Tihanyi T, Szlavik R and Flautner L: Pancreatic pseudocysts causing compression symptoms. Acta chirurgica Hungarica 34: 59-67, 1994.

23. Kim YH, Saini S, Sahani D, Hahn PF, Mueller PR and Auh YH: Imaging diagnosis of cystic pancreatic lesions: Pseudocyst versus nonpseudocyst. Radiographics 25: 671-685, 2005.

24. Pop F, Găvan T, Maxim C, Sorescu S and Vlad L: Pancreatic pseudocyst-diagnosis, evolution, surgical treatment. Chirurgia (Bucur) 99: 131-137, 2004 (In Hungarian).

25. Yeo CJ, Bastidas JA, Lynch-Nyhan A, Fishman EK, Zinner MJ and Cameron JL: The natural history of pancreatic pseudocysts documented by computed tomography. Surg Gynecol Obstet 170: 411-417, 1990.

26. Alhajii W, Nour-Eldin N-EA, Naguib NN, Lehnert T, Koitka K and Vogl TJ: Pancreatic pseudocyst eroding into the splenoportal venous confluence and mimicking an arterial aneurysm. Radiol Case Rep 4: 234-234, 2016.

27. Rabie ME, El Hakeem I, Al Skaini MS, El Hadad A, Jamil S, Shah MT and Obaid M: Pancreatic pseudocyst or a cystic tumor of the pancreas? Chin J Cancer 33: 87-95, 2014.

28. Xiao B and Zhang XM: Magnetic resonance imaging for acute pancreatitis. World J Radiol 2: 298-308, 2010.

29. Case BM, Jensen KK, Bakis G, Enestvedt BK, Shaaban AM and Foster BR: Endoscopic interventions in acute pancreatitis: What the advanced endoscopist wants to know. Radiographics 38: 2002-2018, 2018.

30. De Angelis P, Romeo E, Rea F, Torroni F, Caldaro T, Federici di Abriola G, Foschia F, Caloisi C, Lucidi V and Dall'oglio L: Miniprobe EUS in management of pancreatic pseudocyst. World J Gastrointest Endosc 5: 255-260, 2013.
31. Chahal P, Baron TH, Topazian MD and Levy MJ: EUS-guided diagnosis and successful endoscopic transpapillary management of an intrahepatic pancreatic pseudocyst masquerading as a metastatic pancreatic adenocarcinoma (with videos). Gastrointest Endosc 70: 393-396, 2009.

32. Sperti C, Pasquali C, Guolo P, Polverosi R, Liessi G and Pedrazzoli S: Serum tumor markers and cyst fluid analysis are useful for the diagnosis of pancreatic cystic tumors. Cancer 78: 237-243, 1996.

33. Zhang TP, Zhao YP, Yang N, Liao Q, Pan J, Cai LX and Zhu Y: Evaluation and selection of different procedures in the treatment of pancreatic pseudocyst. Zhonghua Wai Ke Za Zhi 43: 149-152, 2005 (In Chinese)

34. Heider R, Meyer AA, Galanko JA and Behrns KE: Percutaneous drainage of pancreatic pseudocysts is associated with a higher failure rate than surgical treatment in unselected patients. Ann Surg 229: 781-789, 1999

35. Akshintala VS, Saxena P, Zaheer A, Rana U, Hutfless SM, Lennon AM, Canto MI, Kalloo AN, Khashab MA and Singh VK: A comparative evaluation of outcomes of endoscopic versus percutaneous drainage for symptomatic pancreatic pseudocysts. Gastrointest Endosc 79: 921-928; quiz 983.e2, 983.e5, 2014.

36. Loveday BP, Mittal A, Phillips A and Windsor JA: Minimally invasive management of pancreatic abscess, pseudocyst, and necrosis: A systematic review of current guidelines. World J Surg 32: 2383-2394, 2008.

37. Adams DB and Anderson MC: Percutaneous catheter drainage compared with internal drainage in the management of pancreatic pseudocyst. Ann Surg 215: 571-578, 1992.

38. Jedlicka R: Eine neue operations methode der Pankreascysten. Zentrabl Chir 50: 132, 1923.

39. Chan Núnez C and Jimenez Gonzalez A: Surgical treatment of pancreatic pseudocyst. Rev Gastroenterol Mex 69 (Suppl 3): S119-S120, 2004 (In Spanish).

40. Saul A, Ramirez Luna MA, Chan C, Uscanga L, Valdovinos Andraca F, Hernandez Calleros J, Elizondo J and Tellez Avila F: EUS-guided drainage of pancreatic pseudocysts offers similar success and complications compared to surgical treatment but with a lower cost. Surg Endosc 30: 1459-1465, 2016.

41. Varadarajulu S, Bang JY, Sutton BS, Trevino JM, Christein JD and Wilcox CM: Equal efficacy of endoscopic and surgical cystogastrostomy for pancreatic pseudocyst drainage in a randomized trial. Gastroenterology 145: 583-590.e1, 2013.

42. Barragan B, Love L, Wachtel M, Griswold JA and Frezza EE: A comparison of anterior and posterior approaches for the surgical treatment of pancreatic pseudocyst using laparoscopic cystogastrostomy. J Laparoendosc Adv Surg Tech A 15: 596-600, 2005.

43. Melman L, Azar R, Beddow K, Brunt LM, Halpin VJ, Eagon JC, Frisella MM,Edmundowicz S, Jonnalagadda S and Matthews BD: Primary and overall success rates for clinical outcomes after laparoscopic, endoscopic, and open pancreatic cystgastrostomy for pancreatic pseudocysts. Surg Endosc 23: 267-271, 2009.

44. Cremer M, Deviere J and Engelholm L: Endoscopic management of cysts and pseudocysts in chronic pancreatitis: Long-term follow-up after 7 years of experience. Gastrointest Endosc 35: 1-9, 1989.

45. Varadarajulu S, Lopes TL, Wilcox CM, Drelichman ER, Kilgore ML and Christein JD: EUS versus surgical cyst-gastrostomy for management of pancreatic pseudocysts. Gastrointestinal Endoscopy 68: 649-655, 2008

46. Keane MG, Sze SF, Cieplik N, Murray S, Johnson GJ, Webster GJ, Thorburn D and Pereira SP: Endoscopic versus percutaneous drainage of symptomatic pancreatic fluid collections: A 14-year experience from a tertiary hepatobiliary centre. Surg Endosc 30: 3730-3740, 2016

47. Crinò SF, Scalisi G, Consolo P, Varvara D, Bottari A, Pantè S and Pallio S: Novel endoscopic management for pancreatic pseudocyst with fistula to the common bile duct. World J Gastrointest Endose 6: 620-624, 2014

48. Ortiz V, Yousaf MN, Muniraj T, Jamidar P and Aslanian HR: Endoscopic management of pancreatic duct disruption with large mediastinal pseudocyst. VideoGIE 3: 162-165, 2018.

49. Lerch MM, Stier A, Wahnschaffe U and Mayerle J: Pancreatic pseudocysts: Observation, endoscopic drainage, or resection? Dtsch Arztebl Int 106: 614-621, 2009.

50. Yang D, Amin S, Gonzalez S, Mullady D, Hasak S, Gaddam S, Edmundowicz SA, Gromski MA, DeWitt JM, El Zein M, et al: Transpapillary drainage has no added benefit on treatment outcomes in patients undergoing EUS-guided transmural drainage of pancreatic pseudocysts: A large multicenter study. Gastrointest Endosc 83: 720-729, 2016. 
51. Kato S, Katanuma A, Maguchi H, Takahashi K, Osanai M, Yane K, Kim T, Kaneko M, Takaki R, Matsumoto K, et al: Efficacy, safety, and long-term follow-up results of EUS-Guided transmural drainage for pancreatic pseudocyst. Diagn Ther Endosc 2013: 924291, 2013.

52. Binmoeller KF, Seifert H, Walter A and Soehendra N: Transpapillary and transmural drainage of pancreatic pseudocysts. Gastrointest Endosc 42: 219-224, 1995.

53. Wen J, Liang H, Cai FC, Linghu EQ and Yang YS: Effectiveness and safety of endoscopic ultrasound-guided transgastric or transpapillary drainage in treating pancreatic pseudocyst. Zhongguo Yi Xue Ke Xue Yuan Xue Bao 36: 194-197, 2014 (In Chinese).

54. Donatelli G, Dumont JL, Dritsas S, Cereatti F and Meduri B Think opposite: Biliary guidewire-assisted pancreatic cannulation in chronic pancreatitis for transpapillary pseudocyst drainage. VideoGIE 1: 22-24, 2016.

55. Bhasin DK and Rana SS: Combining transpapillary pancreatic duct stenting with endoscopic transmural drainage for pancreatic fluid collections: Two heads are better than one! J Gastroenterol Hepatol 25: 433-434, 2010.

56. Yao Y, Zhang D, Guo J, Qi K, Li F, Zhu J, Wang D, Chen J, Xu C, Wang L, et al: A novel self-expanding biflanged metal stent vs. tubular metal stent for EUS-guided transmural drainage of pancreatic pseudocyst: A retrospective, cohort study. Medicine (Baltimore) 98: e14179, 2019.

57. Baron TH, Harewood GC, Morgan DE and Yates MR: Outcome differences after endoscopic drainage of pancreatic necrosis, acute pancreatic pseudocysts, and chronic pancreatic pseudocysts. Gastrointest Endosc 56: 7-17, 2002.

58. Cavallini A, Butturini G, Malleo G, Bertuzzo F, Angelini G, Abu Hilal M, Pederzoli P, Bassi C: Endoscopic transmural drainage of pseudocysts associated with pancreatic resections or pancreatitis: A comparative study. Surg Endosc 25: 1518-1525, 2011.

59. Kahaleh M, Shami VM, Conaway MR, Tokar J, Rockoff T, De La Rue SA, de Lange E, Bassignani M, Gay S, Adams RB and Yeaton P: Endoscopic ultrasound drainage of pancreatic pseudocyst: A prospective comparison with conventional endoscopic drainage. Endoscopy 38: 355-359, 2006.

60. Varadarajulu S, Christein JD, Tamhane A, Drelichman ER and Wilcox CM: Prospective randomized trial comparing EUS and EGD for transmural drainage of pancreatic pseudocysts (with videos). Gastrointest Endosc 68: 1102-1111, 2008.

61. Vila JJ, Carral D and Fernández-Urien I: Pancreatic pseudocyst drainage guided by endoscopic ultrasound. World J Gastrointest Endosc 2: 193-197, 2010.
62. Lee BU, Song TJ, Lee SS, Park DH, Seo DW, Lee SK and Kim MH: Newly designed, fully covered metal stents for endoscopic ultrasound (EUS)-guided transmural drainage of peripancreatic fluid collections: A prospective randomized study. Endoscopy 46: 1078-1084, 2014.

63. Siddiqui AA, Kowalski TE, Loren DE, Khalid A, Soomro A, Mazhar SM, Isby L, Kahaleh M, Karia K, Yoo J, et al: Fully covered self-expanding metal stents versus lumen-apposing fully covered self-expanding metal stent versus plastic stents for endoscopic drainage of pancreatic walled-off necrosis: Clinical outcomes and success. Gastrointest Endosc 85: 758-765, 2017.

64. Itoi T, Binmoeller KF, Shah J, Sofuni A, Itokawa F, Kurihara T, Tsuchiya T, Ishii K, Tsuji S, Ikeuchi N and Moriyasu F: Clinical evaluation of a novel lumen-apposing metal stent for endosonography-guided pancreatic pseudocyst and gallbladder drainage (with videos). Gastrointest Endosc 75: 870-876, 2012.

65. Rinninella E, Kunda R, Dollhopf M, Sanchez-Yague A, Will U, Tarantino I, Gornals Soler J, Ullrich S, Meining A Esteban JM, et al: EUS-guided drainage of pancreatic fluid collections using a novel lumen-apposing metal stent on an electrocautery-enhanced delivery system: A large retrospective study (with video). Gastrointest Endosc 82: 1039-1046, 2015.

66. Yoon SB, Lee IS and Choi MG: Metal versus plastic stents for drainage of pancreatic fluid collection: A meta-analysis. United European Gastroenterol J 6: 729-738, 2018.

67. Siddiqui AA, Dewitt JM, Strongin A, Singh H, Jordan S, Loren DE, Kowalski T and Eloubeidi MA: Outcomes of EUS-guided drainage of debris-containing pancreatic pseudocysts by using combined endoprosthesis and a nasocystic drain. Gastrointest Endosc 78: 589-595, 2013.

68. Bhasin DK, Rana SS, Nanda M, Chandail VS, Gupta R, Kang M, Nagi B, Sinha SK and Singh K: Comparative evaluation of transpapillary drainage with nasopancreatic drain and stent in patients with large pseudocysts located near tail of pancreas. J Gastrointest Surg 15: 772-776, 2011.

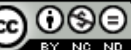

This work is licensed under a Creative Commons Attribution-NonCommercial-NoDerivatives 4.0 International (CC BY-NC-ND 4.0) License. 